\title{
UPP ESTADUAL E UPP FEDERAL: UM ESTUDO SOBRE DUAS FORMAS DE OCUPAÇÃO POLICIAL NO RIO DE JANEIRO'
}

\section{DANIEL GANEM MISSE (UFF)}

Doutor em Ciências Jurídicas e Sociais pelo Programa de Pós-Graduação em Sociologia e Direito. Professor Adjunto do Departamento de Segurança Pública do Instituto de Estudos Comparados em Administração de Conflitos (IAC) e do Programa de Pós-Graduação em Justiça e Segurança (PPGJS) da Universidade Federal Fluminense (UFF). É coordenador do Núcleo de Estudos em Conflito e Sociedade (NECSO/UFF).

\section{JOANA DOMINGUES VARGAS (UFRJ)}

Doutora em Sociologia pelo Instituto Universitário de Pesquisas do Rio de Janeiro. Professora Associada do NEPP-DH Núcleo de Estudos de Políticas Públicas em Direitos Humanos e da Pós-Graduação de Políticas Públicas em Direitos Humanos da Universidade Federal do Rio de Janeiro. Integra o corpo docente do Programa de Pós-Graduação em Sociologia e Antropologia e é Pesquisadora do Núcleo de Estudos da Cidadania, Conflito e Violência Urbana (NECVU) da UFRJ.

\section{PAULO COUTO FILHO (UFRJ)}

Sociólogo, mestre pelo PPGSA - IFCS da UFRJ. Na produção deste artigo atuou como pesquisador com bolsa de iniciação científica pelo Núcleo de Estudos da Cidadania, Conflito e Violência Urbana (NECVU).

\section{RESUMO}

O chamado do governo do estado do Rio de Janeiro para que a Força Nacional de Segurança Pública (FNSP) apoiasse uma "Operação Pacificadora" em 2012 inseriu-se na lógica de uma política de pacificação das favelas cariocas que teve em seu discurso muita similaridade com o modelo das Forças de Paz da ONU. A referência que gestores públicos passaram a fazer com relação à missão da FNSP na favela do Santo Amaro de "UPP Federal" identificava essa intervenção com a estratégia das Unidades de Polícia Pacificadora (UPPs). Importante reduto de venda de crack na zona sul carioca, o Santo Amaro foi ocupado por 150 agentes da FNSP a partir de 18 de maio de 2012, como parte do convênio de cooperação com o governo federal para implementação do programa "Crack, é possível vencer". Já a UPP Santa Marta foi implantada em 19 de dezembro de 2008, sendo a primeira unidade planejada do programa das UPPs criadas por decretos em janeiro de 2009. Este trabalho teve como objetivo realizar uma comparação das formas de atuação policial e da relação com os moradores das ocupações policiais empreendidas pela Força Nacional no Santo Amaro e pela UPP no Santa Marta. A pesquisa de campo foi realizada entre 2014 e 2016, incluindo entrevistas com policiais e moradores, grupos focais e observação de campo, inclusive em reuniões comunitárias. Um dos resultados desta comparação indicou que, em ambas as experiências, os espaços de diálogo com os moradores das favelas ocupadas foram bastante reduzidos. Na UPP Santa Marta o único espaço de diálogo eram os Cafés Comunitários, que ocorriam mensalmente com baixo quórum, enquanto no Santo Amaro não havia espaços de diálogo, sendo reproduzida uma lógica pouco participativa de atuação policial.

1 Este artigo é resultado do Projeto Avaliação de Operações da Força Nacional de Segurança Pública, financiado pela Senasp/MJ; insere-se no Projeto "Passagens de Fronteiras e Cidades Seguras: questões históricas e contemporâneas" (837/15) - Acordo Capes-Cofecub; e contou com bolsistas de iniciação científica da Faperje de Desenvolvimento Acadêmico UFF. Uma primeira versão foi apresentada no GT Violência e Sociedade da Sociedade Brasileira de Sociologia (SBS), em Brasília. 
Palavras-chave: Unidade de Polícia Pacificadora (UPP); Força Nacional de Segurança Pública (FNSP); Rio de Janeiro; Santa Marta; Santo Amaro.

\section{ABSTRACT DYNAMICS PACIFICATION AND OTHER OCCUPATION POLICE TACTICS IN RIO DE JANEIRO.}

In 2012, the government of Rio de Janeiro calls for the National Public Security Force (FNSP) to support him with the pacification policy in the Santo Amaro favela. The reference that public managers began to make regarding the FNSP mission in the Santo Amaro favela of "Federal UPP" identified this intervention with the strategy of the Pacifying Police Units (UPPS). Santo Amaro was occupied as part of the cooperation agreement with the Federal Government to implement the policy "Crack, É Possivel Vencer". The UPP Santa Marta was implemented in 2008, being the first planned unit of the UPPs policy. The study aims to understand the relationship established between law enforcement officials and residents of the affected areas by the police occupation. Field research was conducted between 2014 and 2016, including interviews with police officers and residents, focus groups and field observation. Informal interviews with some locals and policemen were led to identify some types of conflict, analyzing the tense relationship established between both. Also the techniques of direct observation were utilized in community meetings such as the "community cafe" in Santa Marta. The results indicate that despite the lack of contact between the agents of FNSP and UPP Santa Marta, there is much similarity in their approach and relationship established with the locals. It follows a slightly varied militarized structure leading to some questionable community policing activities.

Keywords: Pacification, UPP, National Public Security Force (NPSF), Rio de Janeiro

DOI: 10.31060/rbsp.2020.v14.n2.1049

Data de recebimento: 26/11/2018 - Data de aprovação: 02/06/2019

\section{INTRODUÇÃO}

As Unidades de Polícia Pacificadora (UPPs) foram iniciadas no Rio de Janeiro em 2008, com seus primeiros decretos de criação em janeiro de 2009. A política foi inicialmente planejada para cobrir de 40 a 45 territórios², que corresponderiam a mais de 200 favelas da Região Metropolitana do Rio de Janeiro, até a Copa do Mundo de 2014.

Em 2012, na onda de pacificação das favelas cariocas, o governo do estado do Rio de Janeiro solicitou para a Força Nacional de Segurança Pública (FNSP) apoio em uma "Operação Pacificadora". A operação foi formulada para conter o tráfico de drogas e o consumo de crack na zona sul carioca, na comunidade da Vila Santo Amaro,

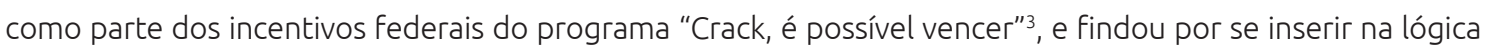
da política de pacificação das favelas cariocas. A ideia inicial era de a Força Nacional realizar o policiamento na comunidade, impedindo o tráfico e consumo de crack, bem como de outras drogas, até que o governo do estado tivesse condições de instalar uma base da Unidade de Polícia Pacificadora (UPP) no morro do Santo Amaro. Devido às similaridades entre a ocupação no Santo Amaro pela FNSP e a estratégia estadual de pacificação das favelas cariocas, gestores públicos passaram a denominar a ocupação de "UPP Federal”.

2 Em diversas entrevistas e atos públicos, ocorridos entre 2011 e 2013, o número de 40 UPPs aparece como referência dita pelo governador do estado do Rio de Janeiro e o secretário de segurança. Entretanto, vale ressaltar que o PPA 2012-2015 previa, para 2014 , "um total de 45 unidades, abrangendo 165 comunidades com aproximadamente 860.000 pessoas. Também é estimado o emprego de aproximadamente 12.500 policiais militares para tal programação" (PPA - Lei 6.126/2011, p. 446).

3 Programa do governo federal criado em 2011 que recebeu destinação orçamentária de 4 bilhões de reais até 2014 para o combate ao consumo e tráfico de crack em cidades brasileiras com mais de 200 mil habitantes. 
Este trabalho tem como objetivo compreender alguns limites discricionários impostos pelo mandato policial por meio de pesquisa de campo realizada em duas ocupações policiais distintas. As ocupações policiais estudadas foram a da Força Nacional no Santo Amaro e a da UPP Santa Marta, na mesma região da capital fluminense.

Situada no bairro da Glória, zona sul do Rio de Janeiro, a comunidade da Vila Santo Amaro, segundo dados do Censo 2010 do Instituto Brasileiro de Geografia e Estatística (IBGE, 2011), conta com 642 domicílios particulares (dos quais 96,8\% são casas e 3,2\%, apartamentos), totalizando 2.173 moradores, sendo $47,2 \%$ homens e $52,8 \%$ mulheres, com uma média de 3,3 habitantes por domicílio. A população é majoritariamente parda (50,9\%) e preta (8,0\%). De acordo com dados produzidos pelo Instituto Pereira Passos (IPP) 14\% dos moradores com mais de 15 anos não são alfabetizados e 62\% das famílias têm renda mensal de até dois salários mínimos.

Em virtude das similaridades sociodemográficas e da relevância para o programa da UPP, escolheu-se a comunidade do Santa Marta como a outra ocupação a ser observada. Situada no bairro de Botafogo, também na zona sul da cidade do Rio de Janeiro, a comunidade do Santa Marta, segundo dados do Censo 2010 do IBGE (2011), tem 1.176 domicílios particulares (dos quais $84,8 \%$ são casas e 15,2\%, apartamentos), totalizando 3.908 moradores. Destes, 48,1\% são homens e 51,9\%, mulheres, com uma média de 3,3 habitantes por domicílio. A população é majoritariamente parda (50,0\%) e preta $(19,1 \%)$. De acordo com dados do IPP, 8,4\% dos moradores com mais de 15 anos não são alfabetizados e 74,8\% das famílias têm renda mensal de até dois salários mínimos.

A escolha dessas duas localidades se deu ainda pelo fato de o efetivo policial de ambas flutuar entre $150 \mathrm{e}$ 200 agentes no período em que foi realizada a pesquisa de campo e de estarem inseridas na Segunda Área Integrada de Segurança Pública (AISP 2) na zona sul da capital fluminense, que compreende os bairros do Catete, Cosme Velho, Flamengo, Glória, Laranjeiras, Botafogo, Humaitá e Urca.

Este trabalho não constitui uma comparação entre políticas públicas, e tem por escopo estudar ocupações policiais distintas. Entende-se que haveria maior dificuldade em comparar a ocupação da Força Nacional ocorrida na Vila Santo Amaro com aquelas da UPP nas zonas norte ou oeste da cidade. Isso se deve a alguns fatores como a conformação histórica do território, a quantidade de policiais empregados em cada ocupação, a dificuldade de acesso à comunidade, o tamanho e a diversidade de facções na mesma localidade e adjacências e perfil demográfico e socioeconômico diverso.

Um estudo comparativo sobre essas duas ocupações policiais permite responder à questão de pesquisa que se debruça, de maneira mais geral, sobre os limites discricionários impostos pelo mandato policial na manutenção da paz e, de forma específica, na relação efetiva estabelecida entre polícia e população nessas duas experiências.

Devido à complexidade imposta pelo estudo de tipos de policiamento, mandato policial e ocupações policiais variadas em apenas uma AISP, a proposta inicial era de incluir uma análise da atuação do 20 Batalhão de Polícia Militar e das reuniões do Conselho Comunitário de Segurança. No entanto, mesmo após autorização para a pesquisa do Comando Maior da Polícia Militar do Estado do Rio de Janeiro (PMERJ), as sucessivas mudanças na cúpula da Polícia Militar fizeram com que novas autorizações tivessem que ser demandadas, o que findou por inviabilizar a pesquisa no Batalhão. Em consequência disso, o campo de pesquisa manteve-se delimitado nas ocupações da Força Nacional no período entre 2014 e 2015 e da PMERJ no Santa Marta em 2015 e 2016, onde está baseada a UPP Santa Marta. 
A pesquisa de campo realizada nessas duas localidades, incluindo entrevistas com policiais e moradores, grupos focais e observação de campo, com participação em reuniões comunitárias, teve como resultado um material riquíssimo que é utilizado apenas em parte neste trabalho. Como forma de melhor interpretar os dados coletados, propõe-se estudar os muitos pontos em comum e dissonantes identificados entre as duas formas de ocupação policial em análise. Para pontuar as questões aqui levantadas, utilizaramse estudos de casos observados nas ações da UPP e da Força Nacional. Por fim, é importante salientar que não foi objeto direto deste estudo a crise da política de pacificação das favelas cariocas, cuja análise necessitaria de um trabalho próprio somente sobre esta temática.

\section{OCUPAÇÕES POLICIAIS EM COMUNIDADES E A POLÍCIA DE PAZ}

Em seu clássico texto "Policiamento em Áreas Deterioradas: um estudo da manutenção da paz", de 1967, Egon Bittner lança algumas questões sobre os problemas da manutenção da paz em áreas deterioradas (skid row), tendo como principal enfoque a relação do policial com os moradores dessas regiões. Para tanto, são apontados três elementos importantes desse enfoque:

Primeiro, o policial mais experiente procura adquirir um conhecimento particularmente rico das pessoas e lugares da área. Segundo, nos motivos para a sanção corretiva, considera a noção estrita de culpabilidade como tendo um status subordinado. Terceiro, sua opção pelo uso de intervenções coercitivas é determinada, principalmente, pelas exigências da situação e pouco se preocupa em relação aos seus efeitos de longo alcance sobre os indivíduos (BITTNER, 2003, p. 54-55).

A ideia de policiais como "funcionários da lei" x "funcionários da paz" (BANTON, 1964) em que o mandato policial deve ser observado como prática para a manutenção da paz, traz luz à discricionariedade da atuação policial ${ }^{4}$. Skolnick (1994) identifica dois tipos de discricionariedades exercidas pela polícia, uma delegada pela lei e outra não autorizada normativamente, mas que evidencia a visão de mundo individual do policial. Esta última discricionariedade ocorre devido a fatores como deficiências na formação policial, baixo grau de supervisão, monitoramento e controle interno da conduta e ação da polícia (MANNING, 1977).

Para Bittner (2003), os procedimentos empregados na manutenção da paz não são determinados por mandatos legais, mas respondem a certas condições de demanda, tais como as produzidas na comunidade, atendendo a um tipo de discricionariedade não delegada por lei. O policial que atua nessas áreas tem como objetivo evitar a desordem e manter um relacionamento pessoal com o maior número de pessoas, aumentando a confiança por um lado e a troca de favores por outro. A relação com os moradores que policiais mais experientes estabelecem de forma dinâmica pelo amplo conhecimento da realidade local é interpretada pela corporação como característica inata de lidar com as pessoas. Esse entendimento errôneo exige de policiais novos as mesmas tarefas e habilidades dos mais velhos, levando a frustrações e "irritabilidade" do profissional. É o policial mais experiente, não uniformizado, e especialmente o patrulheiro que faz ronda a pé, o menos valorizado na divisão do trabalho policial pela crença de que qualquer pessoa poderia fazer esse serviço, bastando "levar jeito".

4 Para MUNIZ e PROENÇA JÚNIOR (2014), a polícia é equipada para o exercício de seu mandato por meio da autorização legal e do consentimento social para policiar, respondendo a qualquer exigência, qualquer situação de perturbação da paz social. Essa conceituação de polícia propõe-se a superar a perspectiva dicotômica de Banton (1964). 
Trojanowics e Bucqueroux (1999)5 buscam explicar os processos organizacionais que levariam ao êxito do policiamento comunitário. Para tanto, propõem o envolvimento dos "seis grandes" (departamento de polícia; comunidade; autoridades civis eleitas; empresários, comerciantes e a comunidade de negócios; outras instituições públicas, sem fins lucrativos e de base comunitária; e a mídia) e a aplicação de dez princípios: filosofia e estratégia organizacional; comprometimento com a concessão de poder à comunidade; policiamento descentralizado e personalizado; resolução preventiva de problemas, a curto e longo prazos; ética, legalidade, responsabilidade e confiança; extensão do mandato policial; ajuda para as pessoas com necessidades específicas; criatividade e apoio básicos; mudança interna; construção do futuro.

O policial comunitário desempenha um papel extremamente importante no processo de patrocínio normativo, pois é pouco frequente o aparecimento de líderes locais que tomem a si a tarefa de resolver os problemas comunitários. Poderão caber ao policial comunitário, como catalisador, as tarefas de estimular o interesse, identificar os líderes e colaborar na solução dos problemas. (TROJANOWICS; BUCQUEROUX, 1999, p. 94).

Para além dos benefícios organizacionais, Skolnick e Bayley (2002) elencam possíveis benefícios do policiamento comunitário para a comunidade envolvida, tais como a possibilidade de melhorar a prevenção do crime, maior atenção com o público por parte da autoridade policial, maior responsabilização da polícia diante da comunidade e encorajamento de esforços para recrutar mulheres e minorias para o trabalho policial, bem como de pessoas com diferentes formações (backgrounds) dentro das forças policiais (com habilidades diferentes para interagir com um público bastante diferenciado, promovendo o valor da heterogeneidade).

A premissa central do policiamento comunitário é que o público deve exercer um papel mais ativo e coordenado na obtenção da segurança. [...][O] público deve ser visto como "co-produtor" da segurança e da ordem, juntamente com a polícia. Desse modo, o policiamento comunitário impõe uma responsabilidade nova para a polícia, ou seja, criar maneiras apropriadas de associar o público ao policiamento e à manutenção da lei e da ordem (SKOLNICK e BAYLEY, 2002, p. 18).

Para os autores até aqui trabalhados, os procedimentos discricionários ${ }^{6}$ empregados na manutenção da paz em ocupações policiais orientadas pela filosofia do policiamento comunitário em áreas deterioradas buscam promover ações colaborativas. Nessas ações, envolvem a comunidade na solução dos problemas por meio de um patrocínio normativo não determinado por mandatos legais, atendendo a um tipo de aplicação seletiva da lei (MUNIZ e PROENÇA JÚNIOR, 2014).

\section{AS OCUPAC̄̃̃ES POLICIAIS NA VILA SANTO AMARO E SANTA MARTA}

Com base nessas questões sobre o mandato policial e a sua discricionariedade para a manutenção da paz, levantaram-se alguns pontos de similaridade e discrepância na atuação policial da Força Nacional no Santo Amaro e da UPP Santa Marta, de sorte a produzir algumas reflexões sobre as formas de atuação policial em ambas as ocupações.

5 Os manuais e ementas dos cursos de formação de polícia comunitária no Brasil e do aprimoramento da prática policial cidadã no Rio de Janeiro vêm difundindo de forma mais ampla determinados paradigmas de policiamento traçados por alguns autores, em especial por Trojanowics e Bucqueroux (1999) e Skolnick e Bayley (2002).

6 Para Kant de Lima (2013), o que se entende por discricionariedade no direito brasileiro está normalmente associado à ideia de obrigatoriedade do processo penal, havendo um estímulo para que a negociação se dê por métodos informais ou pela troca de mercadorias políticas (MISSE, 2006). 


\section{A UPP SANTA MARTA}

Quando a nova ocupação policial da comunidade do morro Santa Marta foi iniciada em 2008, havia acabado de se formar uma Companhia de Policiamento Comunitário no Batalhão de Botafogo. A Major Priscilla, à época ainda Capitão, foi chamada para uma reunião na Secretaria de Segurança para discutir a ocupação da favela e, por conta da sua experiência na tropa, realizando policiamento de rua, foi escolhida para comandar a Companhia que se instalaria no Santa Marta.

As companhias de policiamento comunitário já existiam em alguns batalhões e não havia qualquer bonificação para quem trabalhasse dentro desse setor. Com a ocupação do Santa Marta, Cidade de Deus e Batan e com a proposta do município em pagar uma gratificação aos policiais que realizassem esse tipo de policiamento ${ }^{7}$, houve a necessidade de edição de um decreto para diferenciar esse grupo de policiais dos demais (GANEM MISSE, 2013).

As primeiras "pacificações" se deram por meio de companhias de policiamento comunitário nas comunidades mencionadas, seguidas dos Decretos n 41.650 e 41.653/2009, nomeando esse tipo de policiamento. Uma vez diferenciado dos demais realizados pela polícia, esse tipo de policiamento foi estabelecido como um programa, o que por sua vez possibilitou que os policiais inscritos ou designados recebessem a nova gratificação criada.

Pela estrutura organizacional do Comando da Polícia Militar, as UPPs eram inicialmente subordinadas ao batalhão da área. O comandante do batalhão tinha uma área para comandar que incluía as favelas que teriam um policiamento com uma nova filosofia. Com a criação do Comando de Polícia Pacificadora (CPP), a subordinação aos batalhões foi reduzida a vínculo logístico, servindo principalmente como base de apoio para o policial obter os equipamentos necessários para o seu trabalho diário.

No entanto, apesar das grandes aquisições de equipamentos para as UPPs, ainda ocorriam graves problemas estruturais em diversas bases que estavam relacionados a problemas dos serviços públicos, como a falta d'água, luz, instalações em contêineres improvisados, muitos sem refrigeração, etc. Havia ainda diversas questões relacionadas às condições de trabalho, aceitação da função desempenhada, motivação e formação que foram recorrentemente levantadas pelas tropas.

Do ponto de vista de seu funcionamento, cada UPP apresentava subdivisões na tropa propondo funções distintas para o soldado. Essa divisão administrativa foi sendo parcialmente formalizada, de maneira a ajudar na organização interna das atividades dos policiais ${ }^{9}$. Essa divisão se assemelhava bastante até 2012 ao que ocorria nos batalhões, com tarefas distribuídas entre policiais designados como P/1, P/2, P/3, P/4, $\mathrm{P} / 5$ e o GPP, este último criado de forma diferenciada como um Grupamento de Polícia de Proximidade, reproduzindo em parte a lógica das Companhias de Policiamento Comunitário dos batalhões (GANEM MISSE, 2013, 2014). Ao longo dos anos, essa formatação foi sendo modificada, havendo o registro na pesquisa, finalizada em 2016, da criação do GPP Social, que seria um desdobramento do P/5 (relações

7 Ver matéria do RJTV $2 a$ edição de 18 de dezembro de 2008, em que o governador Sérgio Cabral anuncia essa parceria enquanto inspeciona as obras da estação do metrô General Osório. Disponivel em: <http://rjtv.globo.com/Jornalismo/RJTV/0,_MUL927275-9099,00-FAVELA+DO+BA TAN+SERA+A+PROXIMA+A+RECEBER+POLICIAMENTO+COMUNITARIO.html>. Acesso em: 21 dez. 2017.

8 A Lei n० 7799, de 4 de dezembro de 2017, autorizou o Poder Executivo a subordinar as UPPs aos Batalhões de Polícia Militar nas regiões onde aquelas se localizam, podendo, para tanto, redefinir suas áreas de ocupação e transformando o Comando de Polícia Pacificadora (CPP) em órgão de supervisão.

9 Essa formalização fica evidenciada no Boletim da PM n ${ }^{\circ}$ 040, de 5 de março de 2010, referente à Portaria PMERJ n. ${ }^{\circ} 337$, que regulamenta o Regimento Interno do Comando de Polícia Pacificadora (CPP). 
públicas da unidade), para realizar ações sociais e de cadastramento de moradores. Pelo relato da comandante e de policiais entrevistados, seis setores foram identificados na UPP Santa Marta: Grupo Tático de Polícia de Proximidade (GTPP); Grupo de Polícia de Proximidade (GPP); Administração; Visibilidade; Investigação; GPP Social ${ }^{10}$.

A comandante da UPP Santa Marta, à época da pesquisa, achou importante dar maior ênfase no "social" e propôs uma nova divisão no GPP, criando o GPP Social, substituindo essa função que era acumulada pelo pessoal de relações públicas da unidade. O GPP Social era tido como mais próximo da comunidade, conversando mais com moradores e realizando o seu cadastramento para colher informações em troca de ações assistenciais como a distribuição de cestas básicas e outras doações. Para um dos policiais entrevistados, esse cadastramento era "importante pra saber a situação econômica dos moradores". Esse cadastro continha tanto a situação econômica quanto informações sobre a família, se havia pessoas presas, com vínculo de trabalho e ainda se havia pessoas em drogadição (de álcool e outras drogas). A aproximação do GPP Social se dava nas rondas. Os policiais entrevistados disseram parar para conversar com os moradores até criarem laços, a ponto de posteriormente baterem nas casas e perguntarem "se está tudo bem e se precisam de alguma coisa" (entrevista com policiais do GPP Social, fevereiro de 2016).

Segundo os policiais do GPP Social, os moradores reconheciam os policiais e não se aproximavam do GTPP nem do GPP. A única relação de proximidade era com o GPP Social, que se esforçava para se diferenciar dos outros setores perante a comunidade. O trabalho do GPP Social tinha sido implementado há seis meses quando a pesquisa foi a campo, em 2015. Naquela ocasião, seis policiais participavam do GPP Social, três por turno (dois grupos). O policial entrava no GPP Social voluntariamente, sendo escolhido aquele com o perfil para esse trabalho, isto é, um "talento inato para lidar com as pessoas" (BITTNER, 2003).

Já os policiais do GPP se diferenciavam daqueles do GPP Social pelo tipo de ronda que realizavam. Faziam rondas no interior da comunidade, empreendendo ações intercaladas de visibilidade em determinados pontos da favela, alternando-as com rondas em horários determinados visando coibir o movimento, venda e consumo de drogas.

O GTPP era tido como a "tropa de elite" da UPP, e a equipe era acionada para controlar os "momentos críticos", além de fazer patrulhamento ostensivo e ações de choque. O grupo empregava armamento letal, como o fuzil, e não letal, como bombas de efeito moral e gás. Normalmente atuava a partir de denúncias de moradores ou em situações de "tensão" na UPP.

A aptidão de um policial para "qualquer tipo de serviço" e as demais classificações como "algum tipo de restrição" ou "com problemas graves" determinavam a atividade que o policial poderia realizar. A mais desabonadora, quando aconteciam problemas graves, resultava na perda do porte de arma, sendo normalmente o policial realocado para atividades sociais, de limpeza e manutenção.

Para melhor descrever as relações estabelecidas nas ações de proximidade da polícia com os moradores, selecionaram-se dois relatos de observação de campo (Caso 1 e Caso 2) produzidos por um dos pesquisadores entre outubro de 2015 e junho de 2016.

10 O Boletim Interno do CPP ח० 78, de 5 de maio de 2015, padroniza a escala de serviço das UPPs e apresenta uma divisão um tanto diversa: GPP, GTPP, Relações Públicas, Visibilidade, Permanência, Administração, PROERD, Mediação de Conflito, Núcleo P-2, RUMB, Moto-patrulha, Supervisão de Graduado e Motorista de Supervisão. Isso evidencia certa informalidade das funções atribuídas para o cumprimento do mandato. 


\section{CASO 1: UMA RONDA COM O GPP SOCIAL}

Fomos para a ronda, eu e os dois policiais; ao descer uma escadaria na frente da UPP o ambiente ainda era aberto. Na parte inicial da escada, logo à esquerda, é o caminho para a estação final do plano inclinado. Passada a escada começamos a entrar nas vielas e fomos descendo. Um policial ia na frente e outro atrás de mim. Fomos nesse esquema a ronda toda. No início do trecho das vielas, em um determinado ponto que tinha uma curva para direita, o policial sacou a arma por um momento e espiou antes de fazer a curva, de maneira preventiva. Isso se repetiu umas duas vezes, mas na maior parte da ronda eles andaram com as armas guardadas. Caminhamos um pouco, apenas conversando, até que passamos em frente a uma padaria, um dos policiais parou e me disse pra ir conversar com a dona da padaria, que ele conhecia. Aceitei a sugestão e voltamos. Chegando em frente à padaria, havia uma agente de saúde da família e o policial me sugeriu também conversar com ela. De maneira ríspida, ele orientou o encaminhamento da conversa, dizendo: "Bom dia! Esse senhor está fazendo uma pesquisa, conversa com ele". Eu cumprimentei a dona da padariae fiz algumas perguntas para perceber se ela estava confortável com a situação. Eu não estava preparado para isso, pois meu objetivo era observá-los interagindo com os moradores, mas acho que eles não entenderam muito isso e estavam se esforçando para me ajudar. Eu perguntei se ela era moradora e há quanto tempo; que tipo de trabalho fazia; se as condições de trabalho dela eram boas; e se ela tinha uma relação com a UPP. Todas as respostas foram em tom positivo, mas ela disse que não tinha nenhuma relação [com a UPP]. Mais uma vez o policial falou rispidamente, insistindo para que falasse mais. Ela parecia desconfortável com a situação. Eu refiz as perguntas e ela falou um pouco mais. Disse que havia se mudado havia quatro anos pra lá, só por conta da pacificação, pra poder abrir o negócio dela, pois de outra forma não seria possível. Disse ainda que aprovava a pacificação. Nos dois momentos da conversa, o policial se afastou muito pouco para que eu conversasse com as senhoras, mas ao mesmo tempo [disse] estar disponível para participar se fosse necessário.

Continuamos a caminhada e ao passar por outra casa havia uma senhora na janela do segundo andar; o mesmo policial chamou, de longe, novamente de forma ríspida, a senhora para conversar comigo: "bom dia, a senhora pode descer aqui pra conversar comigo, por favor?!". A senhora desceu bem rápido e apareceu na porta um pouco assustada e constrangida. Ela disse que morava ali na mesma casa a vida toda, 49 anos, e disse estar muito satisfeita com a UPP. Nós estávamos na parte mais alta do morro e ela explicava que a parte de baixo é mais beneficiada por serviços, enquanto a parte de cima é mais precária. Disse que nesse aspecto dos serviços nada mudou, mas que em termos de segurança havia tido "uma melhora nas bagunças naquela área". Ela disse que recebia ajuda da UPP como as cestas básicas e que quando tinha problemas de saúde recorria a eles.

Andamos um pouco mais até que paramos numa área aberta próxima à Laje do Michael Jackson, em frente à porta de uma casa. Ficamos conversando ali por volta de 40 minutos em torno de dois assuntos: a falta de participação da comunidade e alguns comentários depreciativos de outros policiais quanto às suas atividades. De um lado os moradores são relutantes em participar das atividades que eles promovem, a não ser quando a UPP oferece algo, como as cestas básicas, faz eventos como no Natal e na Páscoa, períodos em que os moradores aparecem para pegar o que é oferecido. Nessas ocasiões, eles disseram que são rígidos e só concedem o benefício a quem se cadastra. De outro lado, eles comentaram que já escutaram de colegas comentários depreciativos sobre as suas atividades. Ouviram coisas do tipo "você vai ficar entregando cesta básica?". Comentaram que ocorreu um encontro de policiais de UPPs havia pouco tempo e que quando eles descreveram o que faziam no Santa Marta os policiais de outras UPPs ficaram impressionados e disseram que seria impossível fazer o que eles fazem nas suas unidades. Um dos 
policiais perguntou se eu queria tomar um café em uma loja de souvenires. Enquanto eu conversava com a dona da loja um policial ficou ao meu lado e o outro, bem distante, observando. Foi essa a configuração em todas as conversas com moradores.

\section{CASO 2: O CAFÉ COMUNITÁRIO DA UPP SANTA MARTA}

A reunião do Café Comunitário da UPP Santa Marta ocorria mensalmente em lugares diferentes da comunidade, porém as duas anteriores acabaram não ocorrendo por falta de quórum. A divulgação se dava principalmente por e-mail e Facebook. No dia dessa reunião, que ocorreu em 24 de maio de 2016, eu cheguei às 10 horas para passar o dia com os policiais do GPP Social, porém eles não estavam presentes. Os policiais que fazem o trabalho social são uma espécie de "tapa buraco". São requeridos para realizar diversas tarefas, cuidar de imprevistos, buscar algum documento ou levar policiais a outras unidades. Por conta disso, alguns dos seus serviços com os moradores são adiados e ficam acumulados. Retornei na parte da tarde e um policial me disse que estavam tentando conseguir a doação de um bolo com algum comerciante da comunidade para a reunião da UPP que aconteceria às 18 horas. Fiquei aguardando a reunião, que começou às 18:40. Um pouco antes do início, foi montada uma mesa de lanches e os policiais batiam papo enquanto esperavam as pessoas chegarem. Estavam presentes a comandante, o subcomandante, os dois P5, dois policiais do GPP Social, a policial do GPP que estava presente para divulgar o seu projeto de aulas de dança e a policial que faz projeto de prevenção às drogas nas escolas. Da parte dos moradores estavam presentes o presidente da Associação de Moradores, um jovem que trabalha com turismo comunitário e uma senhora representante da creche, que já tinham participado de outras reuniões em que estive presente. Chegaram em seguida a administradora da Faetec e um homem que estava iniciando projetos culturais na associação. Havia ainda um homem que parecia interessado em se envolver em alguma atividade oferecida, uma senhora que não falou nada durante toda a reunião, mas que era conhecida de todos, e três adolescentes que observavam. Algo que chamou a atenção foi a fala dos dois GPP Social de que nunca haviam estado em nenhuma das reuniões, mas que ali estavam neste dia. A comandante abriu a reunião explicando o seu sentido e reclamando que são sempre vazias, coisa que os moradores mais atuantes repetiram diversas vezes. Um dos participantes repetiu que os moradores só vão às reuniões até resolverem seus problemas. A senhora da creche disse que o problema é a divulgação, que é ruim e tem problemas porque nem todo mundo tem Facebook. Disse ainda que não há divulgação das reuniões nos alto-falantes da comunidade e que estas precisam ter objetivos claros, pautas com assuntos que serão discutidos e resolvidos. A comandante falou sobre a organização do "pico", que consiste na criação do estacionamento perto da base da UPP no alto do morro. Segundo os moradores presentes, essa iniciativa foi bem recebida e teve elogios. Depois falou sobre a atuação do policial que toca o projeto com as escolas de prevenção às drogas. Em seguida anunciou que vai haver um projeto de dança na UPP. O presidente da Associação de Moradores anunciou o início de um projeto com universitários, que vão empreender melhorias na infraestrutura da comunidade. Fez uma fala política longa sobre isso sem explicar muito bem como funcionaria o projeto. A senhora responsável pela creche falou sobre a situação deste equipamento social, das suas dificuldades estruturais, e da invisibilidade do local. Reclamou sobre a postura do Bope quanto à situação da creche, e de que o Bope é muito agressivo forçando a sua entrada na creche. Disse enfaticamente que a polícia não entra na creche e que a enfrentará se necessário, não a deixando entrar. Ao final da reunião, o rapaz que trabalha com turismo comunitário relatou que algumas crianças ficam nas estações esperando os turistas e se oferecem para guiá-los por pontos arriscados, como nas matas. Disse que muitos turistas chegam lá com intenções sexuais e que ele logo se posiciona contrário a essas investidas. Disse que na Copa do Mundo foi um inferno, no que diz 
respeito a essas crianças, e que nas Olimpíadas deverá ser pior. Afirmou estar muito preocupado com as crianças porque será o seu período de férias. Nesse ponto, a comandante sugeriu que fosse criada uma colônia de férias na comunidade.

Em uma primeira análise dos dois casos apresentados, é possível identificar que a proximidade construída pela polícia a partir de rondas a pé, serviços sociais de policiais diferenciados e reuniões comunitárias corresponde ao papel desempenhado pelo policial comunitário descrito pelos autores apresentados na primeira parte deste artigo. No entanto, uma observação mais detida mostra o pouco interesse dos principais grupos sociais do Santa Marta na construção de parcerias colaborativas. As ações colaborativas entre polícia e comunidade para a solução dos problemas são limitadas a espaços esvaziados de reuniões comunitárias sem pautas organizadas e com baixa capacidade de resposta. Em virtude do distanciamento observado entre policiais e moradores mesmo nas rondas do GPP Social, o patrulhamento orientado para a manutenção da paz ganha contornos muito mais próximos de um policiamento para a "manutenção da ordem" (KELLING e WILSON, 1982), em que as rondas a pé poderiam reduzir os "sinais do crime" e de desordem - "uma melhora nas bagunças naquela área", conforme afirmou uma moradora.

A ideia de que a comunidade deve ser ouvida para melhor identificação dos problemas que possam estar ocorrendo na localidade, própria à filosofia do tipo de policiamento voltado para a comunidade, parece esbarrar na participação escassa dos moradores nas reuniões em que estes problemas são discutidos. As percepções sobre serem os moradores pouco participativos, neste caso, estão presentes não apenas entre os policiais, mas também entre os próprios moradores que formulam diferentes explicações para justificar essa ausência. Além de fraca, essa participação parece, em boa medida, restrita às mesmas pessoas. Ainda assim, essa curta descrição traz à tona quais tipos de problemas são trazidos, como esses são definidos pelos moradores e que tipos de respostas são oferecidas, mesmo que apenas esboçadas ou deixadas em aberto.

\section{A FORÇA NACIONAL NA VILA SANTO AMARO}

A Força Nacional de Segurança Pública (FNSP) foi criada em 2004 em um contexto de crise da segurança pública e do sistema penitenciário. Naquele momento pipocavam rebeliões de presos por todo o país e, de forma inédita, atentados a prédios públicos e ataques a policiais, sob o comando de presos vinculados ao Primeiro Comando da Capital (PCC) em São Paulo; conflitos entre povos indígenas e garimpeiros em Rondônia; confrontos constantes entre facções do tráfico no Rio de Janeiro, entre outros.

O projeto de constituição de uma força especial, como a antiga Guarda Nacional, foi iniciado sob a inspiração das Forças da Manutenção de Paz da Organização das Nações Unidas e implantado por meio do projeto Segurança Cidadã, sob o patrocínio do Programa das Nações Unidas para o Desenvolvimento (PNUD). Para tanto, concorreram a experiência e participação em operações de paz, da Brigada Militar e do primeiro comandante do projeto da FNSP - Coronel Aurélio Ferreira Rodrigues -, ainda no início da década de 1990. Os policiais recrutados seguiram a formação dada aos militares, ministrada com base em manuais de instrução elaborados especificamente para as operações de manutenção da paz da ONU (VARGAS et al., 2016).

A FNSP, desde 2007 transformada em Departamento da Força Nacional de Segurança Pública (DFNSP), é coordenada pela Secretaria Nacional de Segurança Pública (Senasp), do Ministério da Justiça. A cadeia de 
comando das missões se exerce com o Ministro da Justiça, o Secretário da Senasp, o Diretor do DFNSP, os responsáveis pelas coordenações e os comandantes das operações, sendo seu mandato estabelecido pelo Decreto no 5289/2004 que delimita as suas atribuições e os procedimentos que devem ser seguidos para o seu emprego. O mandato policial referente à missão é definido por portaria publicada pelo Ministério da Justiça, dando início à operação, que é detalhada em documentos que estipulam, entre outros, como será o emprego da FNSP.

Em 13 de abril de 2012, a prefeitura da cidade do Rio de Janeiro e o governo do estado do Rio de Janeiro assinaram termo de adesão ao programa "Crack, é possível vencer", do governo federal. A ideia inicial da ação era disponibilizar agentes da Força Nacional de Segurança Pública (FNSP) para apoiar ação específica de combate ao crack na comunidade Santo Amaro. Este acordo previa uma operação de cunho "pacificador" em consonância com a política de gestão das favelas cariocas, implementada pelo Programa das Unidades de Polícia Pacificadora (UPPs) do governo do estado do Rio de Janeiro. Como proposta, a Força Nacional deveria permanecer no local para garantir os três eixos do programa: cuidado, autoridade e prevenção.

Cuidado foi o eixo em que se inseriu inicialmente a Secretaria Municipal de Desenvolvimento Social (ainda denominada Assistência Social à época) para acompanhar e encaminhar usuários de crack e outras drogas para centros de tratamento como os Centros de Assistência Psicossocial para Álcool e Drogas (CAPSad) e os Centros de Referência Especializados de Assistência Social (Creas).

As fases de autoridade e prevenção decorreram da ação de presença policial, que seria garantida pela Força Nacional até que o governo do estado do Rio de Janeiro conseguisse, dentro do seu planejamento, formar policiais e inserir uma Unidade de Polícia Pacificadora no local.

Por meio da Portaria nº 769, de 17 de maio de 2012, editada pelo Ministério da Justiça, a Força Nacional de Segurança Pública (FNSP) recebeu a anuência para atuar inicialmente durante o período de 180 dias, sendo que sua permanência foi prorrogada desde então por sucessivas portarias, igualmente com prazos preestabelecidos, até agosto de 2016. O início efetivo do trabalho da FNSP na comunidade Santo Amaro se deu em 18 de maio de 2012, com o auxílio de 174 homens.

Durante a pesquisa de campo, realizada entre junho de 2014 e fevereiro de 2015, observou-se a questão do mandato policial sob os seus dois aspectos. Aquele baseado formal e territorialmente no documento da missão, evidenciado nas falas de seus agentes de que "pode estar quebrando o pau ali que a força não se envolve, ela está amparada aqui" e o outro real, que não foi construído por meio de reuniões comunitárias, nem com participação de lideranças. Não há o interesse dos principais grupos locais no patrocínio normativo, tampouco engajamento da força policial em promover ações colaborativas com a comunidade para a solução dos problemas. Trata-se de um patrocínio normativo não determinado por mandatos legais, um tipo de aplicação seletiva da lei para estender a limitada discricionariedade do mandato policial posta nos documentos da missão.

Muitas falas de agentes da Força Nacional evidenciaram a baixa capacidade de negociação do seu mandato, havendo pouca margem de discricionariedade. Contudo, é interessante ressaltar que sob o ponto de vista corporativo e da percepção que o policial tem sobre suas funções, seu dever de agir e essa limitação do mandato policial, há uma insatisfação por parte do agente.

Na Força Nacional, transparece nas entrevistas a compreensão de que há uma missão específica a ser cumprida, com limites de atuação e que ultrapassar esse mandato pode trazer problemas para o 
policial. No entanto, observou-se que a atuação efetiva transparece de forma mais intensa no cotidiano, principalmente através dos projetos sociais coordenados pelos bombeiros militares, fazendo com que estes adaptem suas escalas de serviço para harmonizar seu trabalho ambulatorial junto à Força com suas atividades sociopedagógicas na comunidade, que não estavam inicialmente previstas.

A relação de diferenciação funcional por meio dos projetos sociais em que só os bombeiros militares fazem projetos, sendo que há uma equipe destacada somente para projetos, ajuda a dar o tom do tipo de mandato policial exercido.

Os projetos sociais não concorrem à escala de guarnição. Quem trabalha no projeto social, só trabalha no projeto social, então nós não temos o horário de 12 por 36 horas. A gente trabalha todos os dias em horário predeterminado, mas é bem flexível [...] porque às vezes nós fazemos eventos no sábado e domingo, às vezes tem passeio sábado de manhã, a gente vai ao Cristo, vai ao Pão de Açúcar, tem colônia de férias que pega o dia todo, então nosso horário pega à tarde e à noite que é quando as mulheres podem fazer a ginástica, porque elas trabalham manhã e tarde, então a gente fica até 21 horas. (Agente da FNSP, entrevista, julho de 2014).

A diferença entre o mandato policial decorrente dos documentos da missão (a autorização legal) e aquele que faz parte da demanda social para policiar no controle da perturbação da ordem ou da paz social pode ser observada na prática cotidiana dos agentes da Força Nacional no Santo Amaro. Durante a pesquisa de campo, acompanharam-se alguns casos interessantes em que se percebeu como era a relação da FNSP com a população e as adaptações feitas em relação ao mandato policial. A seguir, dois casos que permitem melhor compreender a relação entre mandato policial e seu impacto no cotidiano dos moradores da ocupação policial do Santo Amaro.

\section{CASO 1: PROJETOS SOCIAIS}

Acompanhamos os projetos sociais organizados pelos bombeiros da FNSP. Segundo um dos entrevistados, responsável por um dos projetos, há três projetos sendo realizados pelos bombeiros militares: aula de futebol (sextas-feiras às 17h), ginástica para idosos (sextas-feiras às 19h) e aulas de violão (quartas-feiras de manhã na Associação de Moradores). As duas primeiras atividades são realizadas na quadra de futebol da comunidade vizinha conhecida como 715 (comunidade que fica no número 715 da Rua Pedro Américo, próximo ao acesso da Rua Santo Amaro) e compreende tanto moradores do Santo Amaro, quanto daquela comunidade. Outra atividade dos bombeiros é a medição de pressão arterial para as pessoas que os procuram na base e atendimentos de primeiros socorros. Muitos dos agentes da FNSP com quem conversamos afirmaram que somente os bombeiros conseguem acessar determinadas pessoas e lugares no Santo Amaro e na comunidade do 715. Tal reconhecimento foi percebido pelo fato de as oficinas ministradas por eles terem certa procura e periodicidade. Acompanhamos a aula de futebol numa sexta-feira e havia muitos jovens na faixa de idade entre 11 e 14 anos participando da escolinha, mesmo com dias chuvosos.

Observamos que o mandato dos bombeiros não previa a ação social dos bombeiros em nenhum dos documentos da missão a que tivemos acesso. Todavia, o trabalho destes representava o mais importante instrumento de aproximação da Força Nacional com os moradores. O trabalho social paralelo às atividades de ocupação policial também prestava auxílio para casos de acidentes e ambulatoriais para as pessoas que procuravam a Força Nacional. Prestavam tais atividades cobrindo um território que excedia 
aquele determinado pelo mandato formal (o Santo Amaro), atendendo à comunidade de forma ampla, abrangendo moradores da comunidade vizinha, mesmo que alegadamente porque era a única quadra de futebol disponível e com boa estrutura em ambas as comunidades.

É interessante observar que os projetos sociais eram oferecidos somente pelos bombeiros militares. Os policiais militares da Força Nacional não se engajavam em atividades para a comunidade, deixando evidente que havia uma separação entre o que consideravam ser atividade propriamente de polícia.

\section{CASO 2: FESTAS NA QUADRA DA COMUNIDADE DO 715}

Outra situação que pudemos acompanhar foi a negociação em torno da autorização para realização de festas, tanto na comunidade do Santo Amaro como na quadra do 715, cujo território, como já dito, encontrava-se fora da área de atuação da Força. Realizamos nossa pesquisa de campo durante a Copa do Mundo de Futebol de 2014. Havia alguns estrangeiros hospedados nessas comunidades em hostels e nos entornos. Nos dias de jogos do Brasil, a principal entrada da comunidade tornava-se ponto de concentração de torcedores e festas se seguiam ao término dos jogos. Temendo incidentes, o comando da Força estabeleceu limite de horário para as festas, que deveriam ser encerradas até a meia-noite.

Em outras ocasiões também foi comum a negociação com o presidente da associação de moradores do 715, que realiza a cada 15 dias festas na quadra em frente à comunidade, no caminho do Santo Amaro, subindo a Rua Pedro Américo. A negociação se dava em torno da imposição de horário para seu término à $1 \mathrm{~h}$ da manhã, com interrupção do som à 00h30. Para realizar festas na quadra do 715, o presidente da associação de moradores enviava ofício para o comandante geral pedindo autorização para o evento e informando seu horário. Alguns policiais da Força com quem conversamos recordavam-se do último evento, um baile funk, e, naquela ocasião, colocaram duas patrulhas em frente à quadra. O presidente da associação pediu que os carros fossem retirados, pois estavam intimidando as pessoas a aparecerem e "acabando com a festa". Os agentes da Força Nacional avaliaram que o pedido foi feito porque eles queriam vender drogas e que a presença dos policiais estaria inibindo [esse tipo de comércio]. Na festa que acompanhamos, haveria um grupo de pagode e mais uma vez o presidente da associação foi conversar com o oficial de plantão para pedir que a festa terminasse depois de $1 \mathrm{~h}$ da manhã, tendo sido negado o pedido. Um dos soldados nos disse que a festa era feita pra vender drogas e que decidiriam se colocavam ou não uma patrulha lá para acompanhar a festa, já que a quadra ficava fora do Santo Amaro, o que acabou ocorrendo. Segundo o oficial responsável pelo turno, as festas teriam que ter horário para acabar porque atrapalhavam (perturbação da paz) quem queria dormir e também por questões de segurança, para evitar brigas, violência e outros problemas (manutenção da ordem), sendo que a patrulha no local ajudava a prevenção. Muitos outros agentes com que conversamos também disseram o mesmo, frisando a importância de se evitar que as pessoas bêbadas gerassem violência.

Deste modo, a Força Nacional agia contra a "perturbação da paz" na "área deteriorada" fora de seu mandato territorialmente definido nos documentos de missão para garantir a demanda de manutenção da ordem. Ao mesmo tempo em que havia uma limitação em sua atuação por conta da delimitação do território e do objetivo da missão, também havia uma percepção de que para se garantir a segurança do Santo Amaro tinha que se controlar minimamente o entorno, mesmo que não se fizesse patrulhamento na comunidade vizinha, que ainda possuía tráfico de drogas e tinha a sua própria lógica de organização, alheia à ocupação da Força Nacional. 
O objetivo da missão no Santo Amaro, para os agentes da Força, era garantir "uma ação de presença, uma ação ostensiva" como observou um dos entrevistados, ou seja, ter "efetivo ali no local, atuando ali no local [...], ficar indo, porque a gente tem esta movimentação, o pessoal cumpre aqui às 2 horas e desce prá lá, é um trabalho ostensivo com a presença quando a gente está descendo e depois está voltando". Parte dessa ação também incluía a abordagem e a revista de moradores. Para o comandante, "aqui no Rio a nossa missão é de ocupação, é de mostrar a força, é de permanecer, só de a gente permanecer ali os índices criminais já estão eliminados".

Foi apontada como principal dificuldade para o cumprimento do mandato e a realização dos objetivos da missão o fato de que, com a ação de presença no Santo Amaro, o tráfico teria migrado para a comunidade vizinha do 715. Desta forma, a dificuldade de cumprimento do mandato no Santo Amaro teria relação direta com o seu próprio mandato territorializado, que teria obtido êxito em suprimir o tráfico nesta localidade, porém sem ultrapassar essa delimitação territorial. Essa situação trazia a sensação, segundo um outro policial entrevistado, de que "estamos enxugando gelo" e que "logo que sairmos o tráfico estará de volta no mesmo dia". Este mesmo tipo de relato era também elaborado por policiais da UPP, isto é, de que o tráfico voltaria quando a polícia se retirasse e de que perduraria enquanto houvesse favela dominada pelo tráfico.

O comando da missão da FNSP ficava em constante comunicação com o oficial responsável na base dentro da comunidade. Todavia, essa proximidade não era tão grande quanto a de um comandante de UPP, que permanecia dentro da base na própria favela em sua rotina de trabalho e executava a divisão de tarefas diretamente, havendo um oficial responsável para a sua substituição quando necessário.

Nesse sentido, o modelo de "policiamento de proximidade" experimentado no Santo Amaro pela Força Nacional seria intermediário entre o modelo tradicional dos batalhões de polícia militar, em que o comandante realiza apenas funções burocráticas, e aquele experimentado pelas UPPs, em que o comando está na própria unidade, executando tarefas burocráticas e de policiamento em intermediação direta com seus subordinados e legitimado, por isso, como novo dono do morro (CANO, 2012). Outra comparação interessante seria também a proximidade com lideranças comunitárias. Os presidentes das associações de moradores do Santo Amaro e do 715 entravam em contato direto com o comandante por telefone e ofícios, o que também ocorria nas UPPs. No entanto, não se obtiveram registros de reuniões comunitárias organizadas pelos agentes da Força Nacional para discutir temas importantes para a comunidade, algo que apesar de ter se reduzido bastante nos últimos anos nos territórios de UPPs, ainda permaneceu como uma prática comum em algumas favelas pacificadas da cidade, como a Santa Marta. Isto possivelmente se deveu ao princípio de imparcialidade seguido pela Força Nacional, que desconsidera a necessidade de confiança e cooperação da população para o sucesso da missão.

Essa imparcialidade que fundamenta a rotatividade dos agentes da Força Nacional, tendo em vista que os agentes em sua grande parte ficavam no máximo seis meses no mesmo local de trabalho, também ocorreu no caso das UPPS. Estas unidades tiveram alto grau de rotatividade, o que implicou mudanças constantes tanto na gestão como nos policiais de proximidade e nos projetos sociais, levando a um retrabalho de ganhar confiança e restabelecer laços. Diferentemente da filosofia tradicional do policiamento comunitário, em que a relação de confiança é resultante da baixa rotatividade, a percepção que se tinha é a de que laços de confiança poderiam ser construídos facilmente. O importante seria manter a distância, a imparcialidade.

A UPP seria toda baseada na lógica do policial novo na corporação, que não estaria contaminado pelas práticas corruptas e que por isso mesmo não deveria permanecer muito tempo no mesmo lugar, sob pena de se 
contaminar com relações pessoais. Algo parecido foi observado na Força Nacional, em que a rotatividade era tão alta que havia pouca memória da missão e quase nenhum contato com os moradores da comunidade.

Um fato que foi referenciado algumas vezes e que pode ter sido determinante para limitar a compreensão das mudanças e mesmo uma avaliação da missão através da percepção dos agentes da Força Nacional, por exemplo, foi a desmobilização de praticamente toda a tropa da missão em outubro de 2013. Segundo o que foi informado, boa parte do contingente da missão estaria alcançando dois anos de Força Nacional naquele mês, sendo exigida a sua desmobilização e retorno para a instituição de origem. Com isso, praticamente todos os agentes da missão mudaram. Isso gerou forte impacto no policiamento, pois poucos soldados permaneceram na missão, sendo estes também recém-chegados ao Rio de Janeiro. Com a nova tropa que chegou, por falta de memória da missão anterior, produziu-se um desconhecimento do contexto e da dinâmica local por parte da Força Nacional.

\section{CONSIDERAÇÕES FINAIS}

Neste trabalho observou-se que os espaços de diálogo da polícia com os moradores das favelas ocupadas eram bastante reduzidos. Na UPP Santa Marta os Cafés Comunitários constituíam o principal espaço de diálogo, mas ocorriam mensalmente com baixo quórum, quando não eram inviabilizados por não haver qualquer morador presente. Já no Santo Amaro, durante a ocupação da Força Nacional, não havia espaços de diálogo, sendo produzida uma lógica não participativa de atuação policial.

Apesar de a Força Nacional não ter um comandante na base, o que poderia dar maior liberdade de agir aos seus agentes, seu mandato pareceu ser aplicado de forma mais rígida e mais afastada da comunidade do que aquele produzido pela UPP. A discricionariedade maior ou menor, situada entre "governo de leis" e "governo de homens", não pareceu ter qualquer parcela de responsabilidade na construção de um policiamento mais ou menos participativo nos casos estudados.

Por conta da presença constante do comandante ou do subcomandante da UPP na base, o patrocínio normativo não determinado por mandatos legais produziu poucos efeitos na atuação policial individual. A discricionariedade ganhou contornos de atribuições administrativas dadas pelo comando ou concedidas como parte da função do "social" da UPP ou da Força Nacional. O social na ocupação do Santo Amaro não era parte da polícia, mas dos bombeiros militares, e no Santa Marta era prestado por meio de atividades não incorporadas como próprias da polícia pacificadora. Um grupamento "social" foi criado para produzir aproximação por meio de visitas e cadastramento de moradores, produzindo novas formalidades nessa relação, enquanto as demais divisões da UPP seguiam horários fixos estabelecidos por escalas de serviço assemelhadas às dos batalhões, de forma a se burocratizar com rondas programadas e ações de presença.

O mandato policial exarado na forma de atos administrativos concretos, como portarias e boletins de serviço, delimitou o território e a conformação da missão. Isso não impediu que a discricionariedade do exercício do poder de polícia encontrasse novos caminhos para a sua produção. Se por um lado a rotatividade policial era intensa, produzindo pouco conhecimento do território e um afastamento natural com relação à vida da comunidade (o policial antigo não era valorizado e estimulado como parte importante dessas ocupações), por outro, os papéis bem divididos, mesmo que transitórios, possibilitavam que os moradores reconhecessem aqueles com os quais poderiam se relacionar, apesar de sentirem-se entre 0 fogo cruzado e o campo minado (MENEZES, 2015). 
Um fator pouco explorado neste trabalho e que pode ter contribuído para a falta de proximidade entre moradores e policiais nas duas ocupações estudadas consistiu na expectativa de transitoriedade, que de certa forma se confirmou. Havia uma crença por parte dos moradores de que as ocupações policiais nas favelas cariocas só permaneceriam até o fim das Olimpíadas. De fato, a FNSP deixou o Santo Amaro em agosto de 2016. Nesse momento, a população que só conhecia a PMERJ de antes, do 20 Batalhão de Polícia Militar, não viu a passagem para a entrada de uma UPP no lugar. Não foi construída uma relação próxima entre a Polícia Militar do Estado do Rio de Janeiro (PMERJ) e a Força Nacional para garantir "a troca de comando" na comunidade. Com a entrada da Força Nacional, o 20 Batalhão de Polícia Militar se afastou da área e nenhuma informação sobre as UPPs vizinhas foi passada para a FNSP.

No mesmo período, a política de pacificação das favelas cariocas passou por uma grave crise, intensificada com a crise econômica e política do governo do estado do Rio de Janeiro a partir de 2015. A interrupção da atualização e divulgação de dados no Portal da UPP na internet, já a partir do segundo semestre de 2016, a submissão das UPPs aos batalhões de polícia militar de área, a partir de 2017, e a sua "readequação" após a intervenção federal militarizada na segurança pública iniciada no estado do Rio de Janeiro em 17 de fevereiro de 2018, apontam um processo de diluição e interrupção das estratégias do programa. A falta de confiança de moradores (BURGOS et al., 2011; CANO, 2012; RODRIGUES et al., 2012; GANEM MISSE, 2013) e policiais (CESEC, 2011; MUSUMECI, 2015) na permanência da política das UPPs após os grandes eventos tornou-se uma profecia que se autorrealizou.

\section{REFERÊNCIAS BIBLIOGRÁFICAS}

BANTON, Michael. The Policeman in the community. New York: Basic Books, 1964.

BITTNER, E. Aspectos do trabalho policial. Tradução Ana Luísa Amêndola Pinheiro. São Paulo: Edusp, 2003.

BRASIL. IBGE. Instituto Brasileiro de Geografia e Estatística. Censo 2010 Aglomerados Subnormais. Disponível em: <https://censo2010.ibge.gov.br/agsn/>. Acesso em: 12 set. 2018.

BURGOS, M.; PEREIRA, L.; CAVALCANTI, M.; BRUM, M.; AMOROSO, M. O Efeito UPP na Percepção dos Moradores das Favelas. Desigualdade \& Diversidade - Revista de Ciências Sociais da PUC-Rio, $n^{\circ} 11, p$. 49-98, ago.-dez. 2011.

CANO, Ignácio (Coord.) Os Novos Donos do Morro. Rio de Janeiro: UERJ/LAV, 2012.

CESEC. Unidades de Polícia Pacificadora: O Que Pensam Os Policiais. Relatório de Pesquisa. Rio de Janeiro: Universidade Candido Mendes/CESEC, mar. 2011.

GANEM MISSE, D. Cinco anos de UPP: Um breve balanço. Dilemas: Revista de Estudos de Conflito e Controle Social, v. 7, n. 3, p. 675-700, jul.-set. 2014.

GANEM MISSE, D. Políticas Sociais em Territórios Pacificados. Tese (Doutorado em Sociologia e Direito).Universidade Federal Fluminense, Rio de Janeiro, 2013.

KANT DE LIMA, Roberto. Entre as leis e as normas: Éticas corporativas e práticas profissionais na segurança pública e na justiça criminal. Dilemas: Revista de Estudos de Conflito e Controle Social, v. 6, n. 4, p. 549580, out.-dez. 2013.

KELLING, George L.; WILSON, James Q. Broken windows: the police and neighborhood safety. Atlantic Monthly, v. 249, n. 3, p. 29-38, mar. 1982. 
MANNING, P. K. Police Work: the social organization of policing, Cambridge: MIT Press, 1977.

MENEZES, Palloma. Entre o "fogo cruzado" e o "campo minado": uma etnografia do processo de "pacificação" de favelas cariocas. Tese (doutorado em sociologia)-Instituto de Estudos Sociais e Políticos da Universidade do Estado do Rio de Janeiro, Rio de Janeiro, 2015.

MISSE, Michel. Crime e violência no Brasil contemporâneo: estudos de sociologia do crime e da violência urbana. Rio de Janeiro: Lumen Juris, 2006.

MUNIZ, Jacqueline O.; PROENÇA JÚNIOR, Domício. Mandato Policial. In: LIMA, Renato Sérgio de.; RATTON, José Luiz; e AZEVEDO, Rodrigo Ghiringhelli. (Orgs). Polícia e justiça no Brasil. 1. ed., 1ª reimpressão. São Paulo: Contexto, 2014.

MUSUMECI, Leonarda. "Eles nos detestam": Tropeços do policiamento de proximidade em favelas. Boletim Segurança e Cidadania, n. 19, nov. 2015.

RODRIGUES, A.; SIQUEIRA, R.; LISSOVSKY, M. (Org.). Unidades de Polícia Pacificadora. Comunicações ISER, ก. 62, ano 31, 2012.

SKOLNICK, Jerome H. Justice Without Trial: Law Enforcement in Democratic Society. $3^{\mathrm{a} e d .}$, Londres: Wiley, 1994.SKOLNICK, Jerome H.; BAYLEY, David H. Policiamento Comunitário: questões práticas através do mundo. Tradução Ana Luísa Amêndola Pinheiro. São Paulo: Edusp, 2002.

TROJANOWICZ, R.; BOUCQUEROUX, B. Policiamento Comunitário: como começar. Rio de Janeiro: Polícia Militar do Estado do Rio de Janeiro, 1999.

VARGAS, J. D.; MISSE, D. G.; GRILLO, C.; OLIVEIRA, T. C. M.; MARTINS JUNIOR, C. et al. Avaliação de Operações da Força Nacional de Segurança Pública. In: PARESCHI, Ana Carolina Cambeses; ENGEL, Cíntia Liara; BAPTISTA, Gustavo Camilo; NEVES, Alex Jorge das (Org.). Investigação Criminal e Avaliação de Políticas de Segurança Pública. Brasília, DF: Ministério da Justiça, 2016. p. 79-118. Coleção Pensando a Segurança Pública. v. 7. 


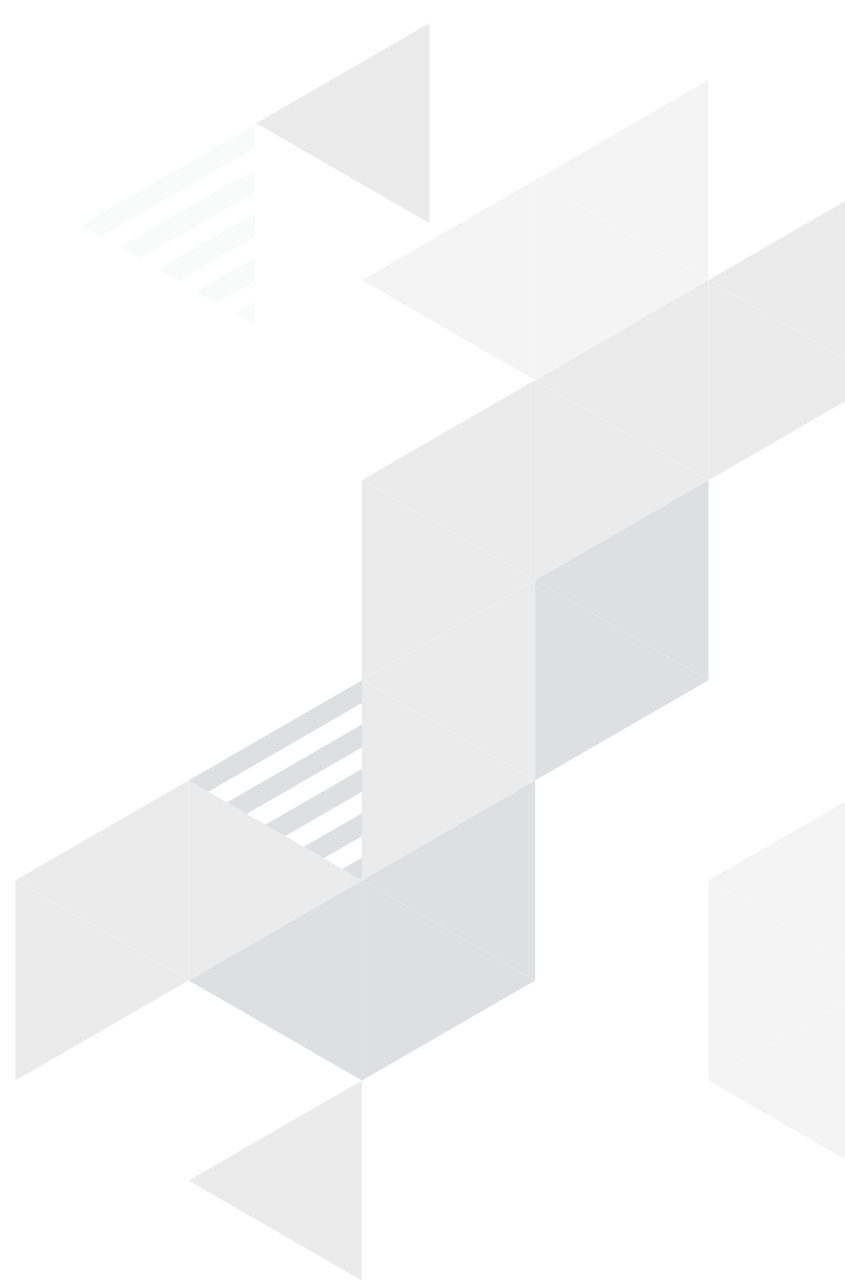

